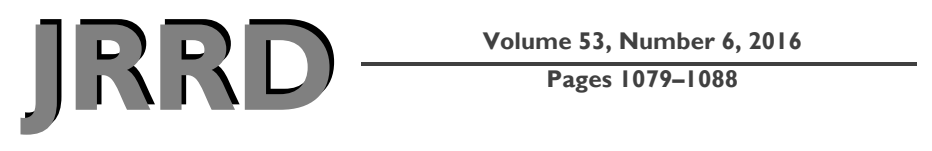

\title{
Metabolic effects of using a variable impedance prosthetic knee
}

\author{
Matthew R. Williams, PhD; ${ }^{1-2 *}$ Hugh Herr, PhD; ${ }^{1-2}$ Susan D’Andrea, PhD $^{1,3}$ \\ ${ }^{1}$ Providence Department of Veterans Affairs Medical Center, Providence, RI; ${ }^{2}$ Media Lab, Massachusetts Institute of \\ Technology, Cambridge, MA; ${ }^{3}$ Department of Orthopaedics, Brown University, Providence, $R I$
}

\begin{abstract}
A transfemoral amputation has a significant effect on walking. Though current prosthetic knee options serve to restore mobility, as purely passive devices, they do not fully restore nondisabled gait. Persons with transfemoral amputation incur a higher metabolic cost during walking than persons without amputation and as a result walk slower and for shorter distances before tiring. An original variable-impedance transmission prosthetic knee (VI Knee) was tested in five study participants with unilateral transfemoral amputation at two steadystate walking speeds, one below and one above their preferred walking speed. While walking with the VI Knee, participants with shorter limbs showed a reduction in metabolic cost compared with their conventional C-Leg prosthesis, while those with longer limbs exhibited an increase. Though differences were observed between speeds, overall the difference in metabolic cost (reduction or increase) was found to correlate significantly with rise in the center of mass, with those with shorter residual limbs exhibiting less overall lifting of the body during gait.
\end{abstract}

Key words: amputation, center of mass, gait, knee joint, metabolic cost of transport, prosthesis, rehabilitation, robotics, transfemoral, walking.

\section{INTRODUCTION}

Across the United States, there are more than 270,000 people with transfemoral amputation, with an incidence rate of approximately 39,000 cases yearly [1]. Within the Veteran population, the Department of Veterans Affairs (VA) performs approximately 1,500 to 2,000 transfemoral amputations yearly [2]. The largest portion of these results from vascular disease as a complication of diabetes. However, with continuing military actions abroad, an increasing number of service personnel are suffering lower-limb trauma requiring amputation above the knee. One recent study found that approximately 34 percent of recent combat injuries requiring amputation resulted in a transfemoral amputation [3].

The design of a biomimetic knee prosthesis is based upon the fundamentals of nondisabled forward walking. Biomechanical models of walking have shown that much of the leg's behavior during gait can be accomplished using passive energy storage elements at the various joints [4]. Series elastic actuators have been used in several walking robots over the years as they provide more lifelike motions, have inherent impact tolerance, and ease control requirements [5-6]. While walking over level ground, energy is largely conserved via storage, transfer, and timed discharge of potential energy with minimal propulsive input needed from the hip. During gait, potential energy is stored kinetically by raising the body or elastically in the tendons of the legs [7]. In models, by combining passive actuators (springs) with clutches to activate and deactivate these actuators during walking, much of the mechanical energy produced can be stored

\footnotetext{
Abbreviations: $\mathrm{COM}=$ center of mass, $\mathrm{MCOT}=$ metabolic cost of transport, VA = Department of Veterans Affairs.

*Address all correspondence to Matthew R. Williams, PhD; 10701 East Blvd, Cleveland, OH 44106; 216-3925062; fax: 216-231-3258. Email: mwilliams@fescenter.org http://dx.doi.org/10.1682/JRRD.2015.04.0072
} 
and used at later phases of the gait cycle. This is similar to nondisabled level-ground walking; muscle activity at the knee is largely associated with energy absorption and storage rather than power generation [8]. In contrast, current prosthetic knee technologies primarily disperse mechanical energy (converting it into heat) while supplying braking forces to the knee during leg swing [9].

The most clinically advanced prosthetic knees, such as the earlier C-Leg and more current Genium (Ottobock; Duderstadt, Germany) and the Rheo (Össur hf; Reykjavík, Iceland), available today are able to control damping during gait, can adapt to different walking speeds, and are an improvement over older, simpler knee mechanisms [10]. These state-of-the-art devices, however, are still passive devices, incapable of storing and releasing mechanical energy during walking or providing positive power throughout the gait cycle. As a result, persons with a transfemoral amputation using current standard-of-care knee prostheses have metabolic costs approximately 33 percent higher than persons without amputation during levelground walking and tend to walk approximately 45 percent slower to compensate for the increased physical demand [11]. Notably, they fatigue sooner and are able to walk shorter distances than persons without amputation.

Within the population of individuals with transfemoral amputations, significant effects to gait kinematics and kinetics have been shown to be related to the residual limb length (proportion of remaining femur length to original preamputation length) [12-13]. In general, those with shorter residual limbs have overall less lever arm with which to propel the body and weaker hip stabilizers, resulting in greater deviation from nonpathologic gait $[7,12-13]$. This leads shorter-limbed people with transfemoral amputation to walk slower in order to minimize their energy expenditure [14-15].

While the overall study of powered prosthetic knees goes back several decades, a few groups have only just realized the challenge of a prosthetic with the power supply, motors, and control electronics all contained within the device [16-20]. The work of Sup et al. has resulted in a combined knee-ankle powered prosthesis that can approximate the kinematics of nondisabled walking over level ground and up-slope ambulation using onboard sensors to control prosthesis gait [21-22]. Commercially, Össur hf is marketing the Power Knee, a direct-drive, servo-controlled device that uses motion of the soundside leg to determine prosthetic knee position [23-24]. These earlier attempts to restore knee function, while allowing for powered walking, have largely not fully leveraged the benefits of energy conservation (storage and controlled release) that can be afforded by passive, elastic elements incorporated into the design of the device.

Research by Martinez-Villalpando and Herr [25] has resulted in the advancement of a variable-impedance prosthetic knee, VI Knee (Massachusetts Institute of Technology; Cambridge, Massachusetts), using series-elastic actuators in an agonist-antagonist arrangement to control knee impedance, or both knee damping and stiffness. The agonist-antagonist actuation strategy described in MartinezVillalpando and Herr allows each motor to operate primarily while unloaded to set the spring equilibrium of the joint, reducing the overall electrical demands of the device [25]. Opposing series-elastic actuators allow for a device that can store and discharge mechanical energy using its physical series-elastic elements during each phase of levelground walking and that also can vary the knee damping, effective joint spring equilibrium position, and stiffness electronically. Such a variable-impedance control allows the knee to adjust its output (producing positive elastic torque or braking torque) in relation to its rotational state (position and velocity) to replicate a more natural gait, enhancing metabolic effectiveness. In preliminary studies, individuals with transfemoral amputation walking at their customary speed over level ground were found to have reduced their metabolic effort by 6.8 percent while walking with this knee compared with their normal variable-damping prosthesis, despite its greater mass $(2.5 \mathrm{~kg}$ vs $\approx 1.5 \mathrm{~kg}$ for C-Leg with pylon and fittings) [26].

This study more thoroughly investigated the metabolic and underlying differences in biomechanics between walking with the VI Knee compared with the C-Leg (the current standard-of-care prosthetic knee for active walkers). This case series study was performed across a range of residual limb lengths and at speeds below and above participants' customary walking speeds. We hypothesized that by using a knee with active rotation, the wearer's metabolic cost would be reduced at speeds both lower and higher than their customary walking speed as a result of the novel device's capability to store and release energy as well as provide motive power.

\section{METHODS}

The device tested in this investigation was the previously described VI Knee developed at the Massachusetts 
Institute of Technology (Figure 1(a)) [25]. Five subjects with unilateral, transfemoral amputation subjects were recruited through area prosthetists using the inclusion criteria previously reported in Williams et al. [27]. All subjects were experienced C-Leg users and spanned a range of years since amputation and a range of residual limb lengths (Table 1). Subjects participated in three experimental sessions: (1) a initial fitting of the VI Knee by a certified prosthetist and tuning of the device to their gait [27], (2) a metabolic testing session, and (3) a biomechanics testing session. Each session was performed on a different day at the Providence VA Medical Center Gait Laboratory.

The metabolic testing consisted of having subjects wear a portable breath-by-breath cardiopulmonary exercise tester (K4b2, Cosmed; Rome, Italy) (Figure 1(b)) while walking using either their current C-Leg or the VI Knee prosthesis. Subjects were instructed to abstain from eating or consuming any caffeine for $3 \mathrm{~h}$ prior to the testing to mitigate digestive or chemical effects on metabolism. Prior to the walking experiments, a 7 min quiet standing trial (while on their conventional prosthesis) was recorded to determine subjects' baseline metabolic rate. The session started with 30 min of practice with the VI Knee to become reac-

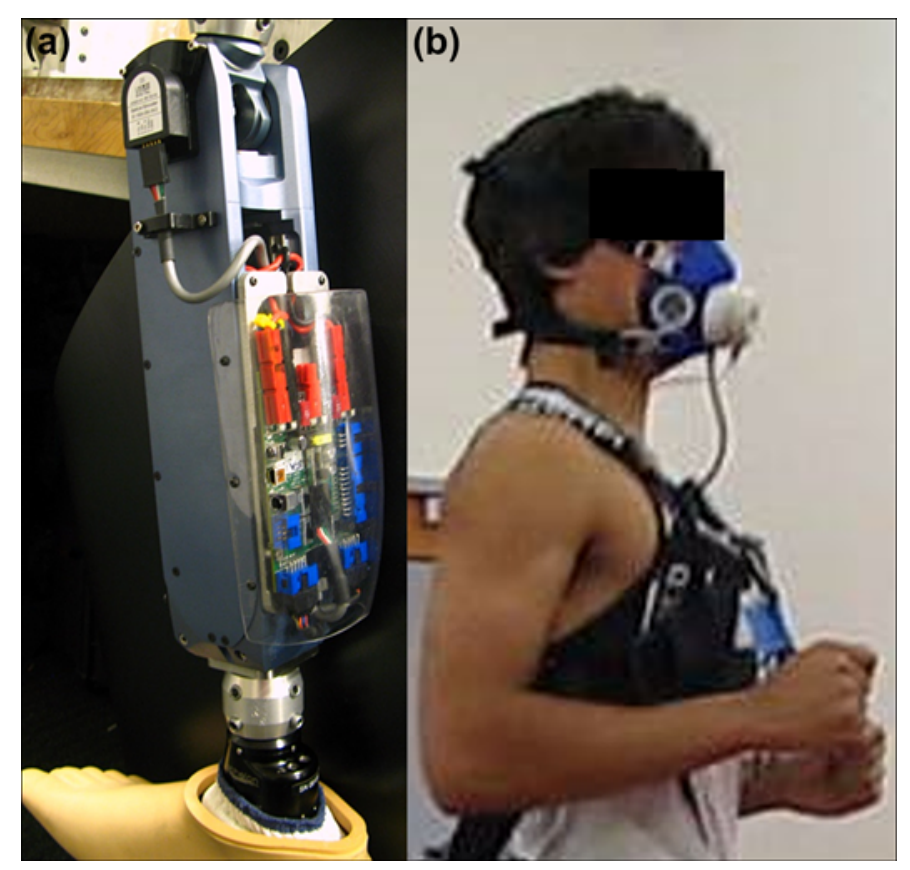

Figure 1.

Photographs of (a) VI Knee with prosthetic foot attached and (b) subject wearing cardiopulmonary exercise tester. quainted with the device followed by a 10 min rest period. Subjects then walked continuously with each knee at $1 \mathrm{~m} / \mathrm{s}$ or $1.25 \mathrm{~m} / \mathrm{s}$ for $7 \mathrm{~min}$ around a vacant hallway circumscribing the building while their $\mathrm{O}_{2}$ consumption and $\mathrm{CO}_{2}$ production were measured. These speeds were used as they represented fixed speeds just outside the subjects' normal, customary walking speeds but were still well within the limits of each subject's walking ability. The order of testing of the prosthetic knee and the speed was randomly assigned. After testing at one speed, subjects rested for $5 \mathrm{~min}$ and then were tested at the other speed. This process was then repeated using the other knee after a 20 min rest. Walking speed was kept by having subjects maintain pace with a research team member who controlled their pace with a metronome calibrated to their gait. Earphones were worn by the pace-setter so that the subject could not hear the beat. Measured gas recordings were filtered by using a 15-breath moving average to account for variability as a result of tidal volume and breathing frequency per Robergs et al. [28]. We then computed the metabolic cost of transport (MCOT) for each subject for each prosthesis condition and speed from the standard equation for calculation of energy expenditure $\left(16.58 \times\right.$ volume $\left.\mathrm{O}_{2}\right)+(4.51 \times$ volume $\mathrm{CO}_{2}$ ) and normalized to each subject's body weight [29].

For the biomechanical analyses, subjects were fitted with infrared reflective markers on the joints and limb segments of the limbs and torso and had their gait recorded as they walked across a 10m walkway. Standard and previously published methods for signal processing and gait analysis were used to assess each subject's gait as he or she walked with either the VI Knee or C-Leg (random order) [27].

Large gait differences between subjects precluded across-subject comparisons, so all statistical comparisons were within subject. To account for differences in variance between conditions (prosthesis), we used Welch's $t$-tests with two tails and alpha $=0.05 ; p \leq 0.05$ was considered significant and values of $0.05<p \leq 0.1$ were classified as trends. Significance testing of correlation comparisons were performed per Cohen et al. [30]. We checked data for comparison normality graphically using normal probability plots.

\section{RESULTS}

The ratio of the MCOT between the VI Knee and CLeg $\left(\mathrm{MCOT}_{\mathrm{VI} \text { Knee }} / \mathrm{MCOT}_{\mathrm{C}-\mathrm{Leg}}\right)$ is illustrated in Figure 2. 
Table 1.

Subject information. All subjects' current prosthetic knee was the C-Leg.

\begin{tabular}{lccccccl}
\hline Subject & $\begin{array}{c}\text { Age } \\
\text { (yr) }\end{array}$ & $\begin{array}{c}\text { Height } \\
\text { (m) }\end{array}$ & $\begin{array}{c}\text { Weight } \\
\text { (kg) }\end{array}$ & $\begin{array}{c}\text { Cause of } \\
\text { Amputation }\end{array}$ & $\begin{array}{c}\text { Time Since } \\
\text { Amputation } \\
\text { (yr) }\end{array}$ & $\begin{array}{c}\text { Residual } \\
\text { Limb } \\
\text { Length (\%) }\end{array}$ & \multicolumn{1}{c}{$\begin{array}{c}\text { Current } \\
\text { Prosthetic Foot }\end{array}$} \\
\hline 1 & 37 & 1.83 & 91 & Trauma & 23 & 60 & Össur* hf Low Profile Re-Flex VSP \\
2 & 49 & 1.75 & 98 & Trauma & 27 & 90 & Össur ${ }^{*}$ Low Profile Vari-Flex \\
3 & 55 & 1.83 & 88 & Cancer & 41 & 100 & College Park $^{\dagger}$ Trustep \\
4 & 52 & 1.75 & 89 & Trauma & 33 & 65 & Ottobock $^{\dagger}$ Triton \\
5 & 61 & 1.78 & 105 & $\begin{array}{l}\text { Vascular } \\
\text { Disease }\end{array}$ & 12 & 80 & Össur ${ }^{*}$ Flex-Walk \\
& & & & & \\
\hline
\end{tabular}

*Located in Reykjavík, Iceland.

${ }^{\dagger}$ Located in Warren, Michigan.

tLocated in Duderstadt, Germany.

Values greater than 100 percent indicate an increase in MCOT as a result of using the VI Knee, and values less than 100 percent denote a decrease in MCOT. This ratio value represents the percent difference in MCOT between the two prostheses relative to each other. At $1 \mathrm{~m} / \mathrm{s}$, three subjects exhibited a significant increase in MCOT while using the VI Knee (dashed circle), and two subjects showed a significant decrease (solid circle) between conditions (Figure 2(a)). At $1.25 \mathrm{~m} / \mathrm{s}$, two subjects had a significant increase in MCOT (dashed circle), and three exhibited a significant decrease in MCOT (solid circle, Figure 2(b)). Figure 2 also illustrates the correlation between MCOT ratio and residual limb length for $1 \mathrm{~m} / \mathrm{s}$ $(0.765)$ and $1.25 \mathrm{~m} / \mathrm{s}(0.763)$.

Tables 2 and 3 show the individual subject differences between the VI Knee and C-Leg for kinematic, kinetic, and metabolic parameters of gait (VI Knee - C-Leg performance) and the correlations computed between each difference and residual limb length, difference in net MCOT, and difference in center of mass (COM) rise area. The relative difference between the performance of each prosthesis was studied as it better captures the overall magnitude and temporal differences in kinematics and kinetics between conditions. We selected these gait parameters for analysis because they were shown to have strong correlations to differences in MCOT between prostheses tested. Significant correlations $(p \leq 0.05, r \geq 0.88)$ and trending relationships $(0.05<p \leq 0.1,0.88>r \geq 0.81)$ are noted. Subject performance is listed in order of residual limb length to illustrate any trends present that are related to this factor.

At $1 \mathrm{~m} / \mathrm{s}$ (Table 2), significant or trending correlations can be seen associated with maximum hip extension moment; hip extension moment (both positive) during stance phase and in knee height area; maximum hip velocity (both negative); and COM height area (positive) in swing when juxtaposed with residual limb length, difference in MCOT, and COM rise. Overall, as shown in Figure 2, there is a strong correlation between difference in net MCOT as a result of using the VI Knee and residual limb length.

A different pattern of significant and trending correlations is seen in Table 3 for participants walking at $1.25 \mathrm{~m} / \mathrm{s}$. At this speed, a negative correlation is seen between stance time and residual limb length, difference in MCOT, and COM rise during stance. During swing, hip height area shows a positive correlation with difference in MCOT and COM rise; hip velocity shows a negative correlation; and COM rise shows a positive, trending correlation with difference in MCOT between conditions. Similar to the lower speed, a positive correlation (trend) is seen between residual limb length and net MCOT difference while using the VI Knee compared with the C-Leg.

The difference between prostheses for kinematic measures was compared as the area under the curve between conditions during either the affected leg stance or swing phase of gait where the two conditions were significantly different from each other. This value represents the total difference between conditions, capturing both the magnitude of the difference as well as the duration of the difference during the gait cycle. An example of this area comparison between devices can be seen in Figure 3, which illustrates an example of a subject with a large significant difference in COM height area (Figure 3(a); redshaded region) and a small COM height area difference (Figure 3(b), purple-shaded region). 
(a)

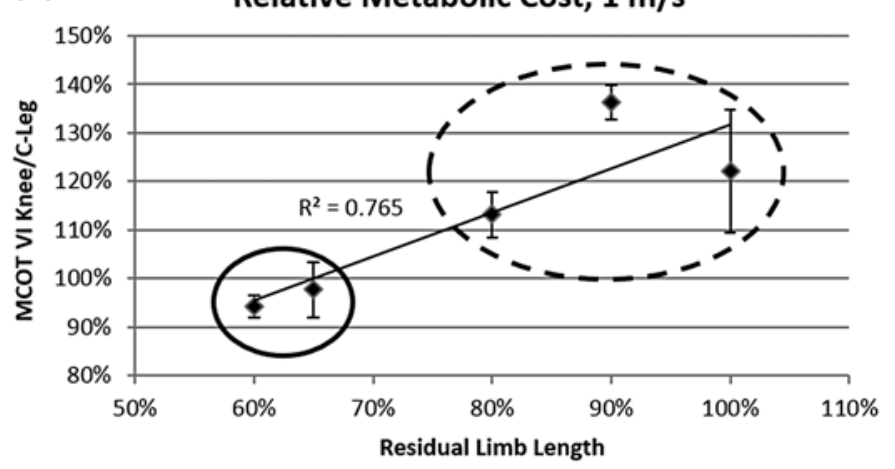

(b)

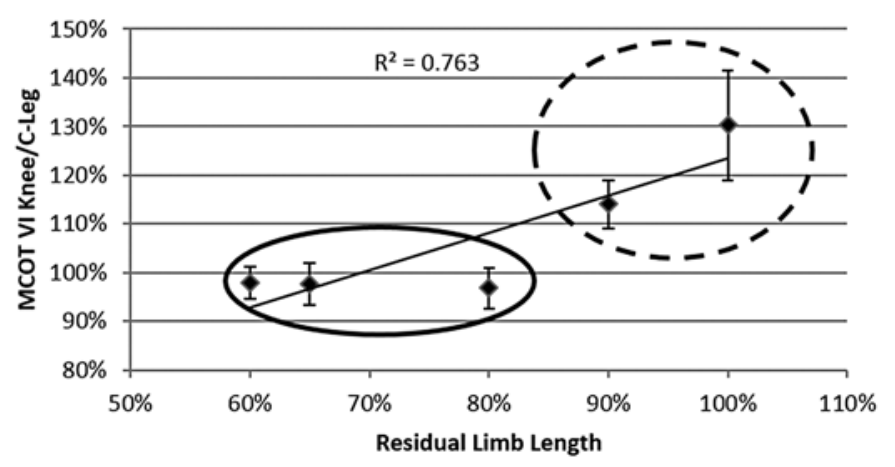

Figure 2.

Relative net metabolic costs of transport (MCOT) as a function of residual limb length between prostheses while walking at (a) $1 \mathrm{~m} / \mathrm{s}$ and (b) $1.25 \mathrm{~m} / \mathrm{s}$. Values less than 100 percent indicate a reduction in MCOT while using the VI Knee (solid circles); values greater than 100 percent an increase due to using the new device (dashed circles).

\section{DISCUSSION}

Metabolic cost is elevated in people with transfemoral amputation because of deviations in gait pattern and gait symmetry and increased involvement of the upper body, particularly in terms of lifting the affected side pelvis resulting in increased lifting of the COM. Previous investigations using a knee prosthesis providing positive power at late stance, flexion, and swing extension showed reductions in MCOT of 6.8 percent, similar to that observed in this work [25]. The reductions, while significant, are not as dramatic as those seen while using a powered ankle because the knee is not as involved in providing motive power as the ankle or hip [11,14,31]. From Figure 2, it can be seen that there are distinct differences in metabolic effects while using the VI Knee compared with a C-Leg; individuals with shorter residual limbs showed a reduction in MCOT and those with longer limbs an increase in metabolic cost - a trend seen at both the lower and, to a lesser extent, the higher speed. While it has been shown previously that residual limb length can have a significant effect on gait [14,32], a better understanding of the effects of limb length on MCOT performance while using the VI Knee is presented in the two tables of correlated gait measures.

At the lower speed, there are significant and trending correlations (positive and negative) across residual limb length, difference in MCOT, and COM rise area (Table 2). From these correlations, longer-limbed individuals exert a larger hip moment on the affected side (both area and maximum), a tendency more common regardless of prosthesis used because of their larger amount of remaining muscle and the longer limb providing a better lever arm with which to push off the ground and propel the body forward [7,11-13]. Conversely, those with shorter residual limbs have a significantly higher knee rise area, which is also strongly correlated with reduction in MCOT and reduction in the rise of COM. Rise of COM is significantly positively correlated with both residual limb length and increase in MCOT while using the VI Knee. Taken in aggregate, at this speed, those subjects who did not push on the ground (to either propel the body forward or lift the COM) and instead used a more marching-like gait to get the affected leg up and "out of the way," lifting the knee to clear the toe, saw reductions in metabolic cost while using the VI Knee. As this style of gait is more similar to how individuals with shorter transfemoral amputations walk as a result of their overall reduced hip torque capacity, they showed the greatest reductions in metabolic cost [11-13].

The patterns of correlated performance measures are distinctly different at the higher $(1.25 \mathrm{~m} / \mathrm{s})$ speed (Table 3). At this speed, longer-limbed individuals show a reduction in affected side stance time while using the VI Knee. At the higher speed, all subjects showed an increase in hip hiking regardless of residual limb length and those who hiked the hip more showed corresponding increases in MCOT and COM rise. Shorter-limbed individuals continue to show a higher hip velocity, which also matches a reduction in MCOT and less COM rise. At this speed, all subjects are lifting the COM with a trend toward this 
Table 2.

Performance differences between prostheses while walking at $1 \mathrm{~m} / \mathrm{s}$ for each subject and their correlation to residual limb length, difference in net metabolic cost of transport (MCOT), and center of mass (COM).

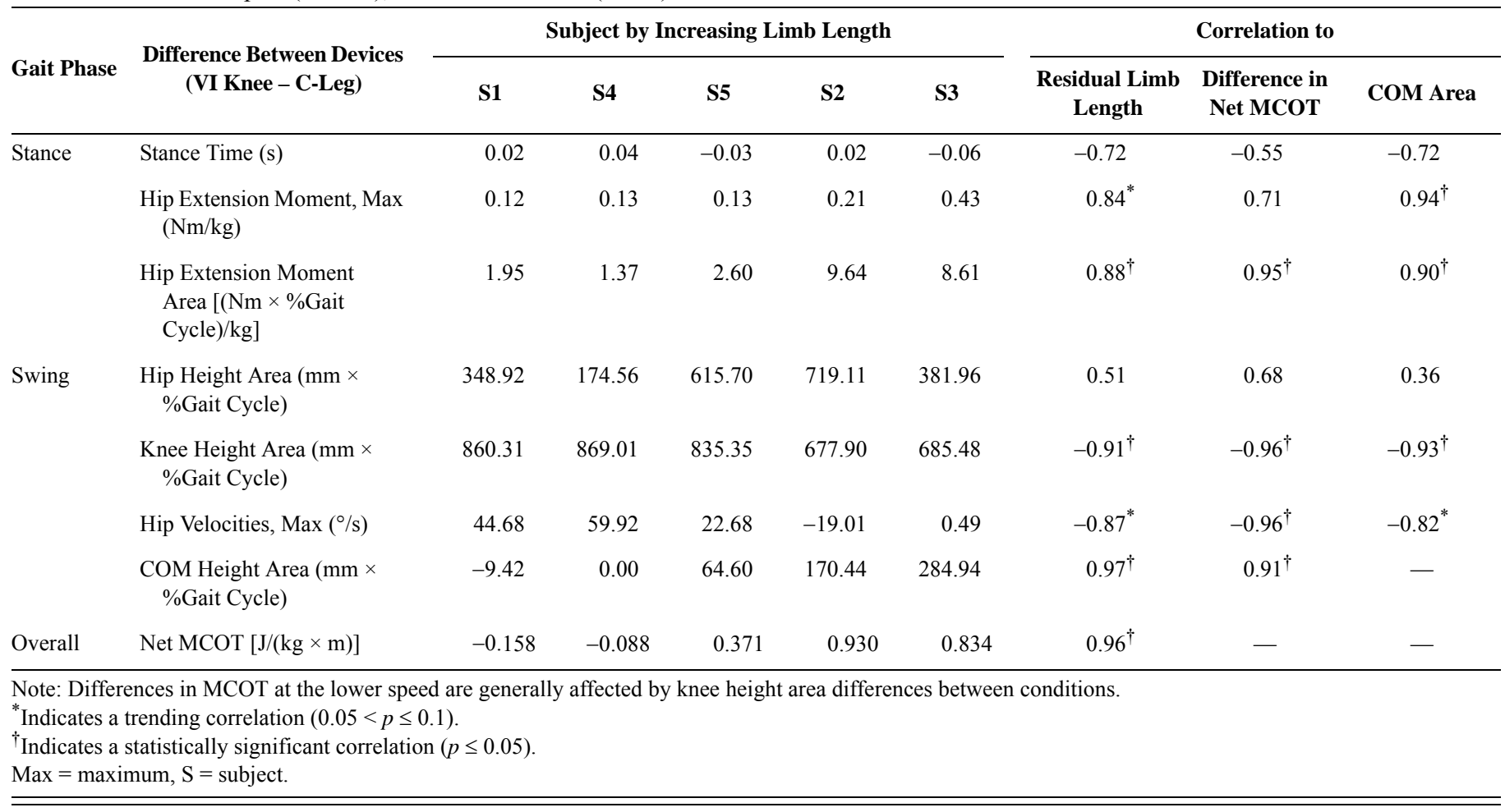

Table 3.

Performance differences between prostheses while walking at $1.25 \mathrm{~m} / \mathrm{s}$ for each subject and their correlation to residual limb length, difference in net metabolic cost of transport (MCOT), and center of mass (COM).

\begin{tabular}{|c|c|c|c|c|c|c|c|c|c|}
\hline \multirow[b]{2}{*}{ Gait Phase } & \multirow[b]{2}{*}{$\begin{array}{c}\text { Difference Between Devices } \\
\text { (VI Knee - C-Leg) }\end{array}$} & \multicolumn{5}{|c|}{ Subject by Increasing Limb Length } & \multicolumn{3}{|c|}{ Correlation to } \\
\hline & & S1 & S4 & S5 & S2 & S3 & $\begin{array}{c}\text { Residual } \\
\text { Limb Length }\end{array}$ & $\begin{array}{l}\text { Difference in } \\
\text { Net MCOT }\end{array}$ & $\begin{array}{l}\text { COM } \\
\text { Area }\end{array}$ \\
\hline & $\begin{array}{l}\text { Hip Extension Moment, } \\
\operatorname{Max}(\mathrm{Nm} / \mathrm{kg})\end{array}$ & 0.21 & 0.23 & -0.12 & 0.40 & 0.23 & 0.16 & 0.34 & 0.29 \\
\hline \multirow[t]{3}{*}{ Swing } & $\begin{array}{l}\text { Hip Height Area }(\mathrm{mm} \times \\
\text { \%Gait Cycle })\end{array}$ & 261.83 & 321.98 & 40.65 & 587.13 & 787.81 & 0.70 & $0.89^{\dagger}$ & $0.83^{*}$ \\
\hline & $\begin{array}{l}\text { Knee Height Area }(\mathrm{mm} \times \\
\text { \%Gait Cycle })\end{array}$ & 30.56 & 1291.84 & 141.08 & 545.31 & 734.15 & 0.09 & 0.21 & 0.12 \\
\hline & Hip Velocities, Max (\%/s) & 40.87 & 50.64 & 25.49 & -32.10 & -41.76 & $-0.94^{\dagger}$ & $-0.86^{*}$ & $-0.96^{\dagger}$ \\
\hline \multicolumn{10}{|c|}{$\begin{array}{l}\text { Note: Differences in MCOT at the higher speed are more } \\
\text { *Indicates a trending correlation }(0.05<p \leq 0.1) . \\
\text { 'Indicates a statistically significant correlation }(p \leq 0.05) \text {. } \\
\text { Max = maximum, } \mathrm{S}=\text { subject. }\end{array}$} \\
\hline
\end{tabular}


(a)

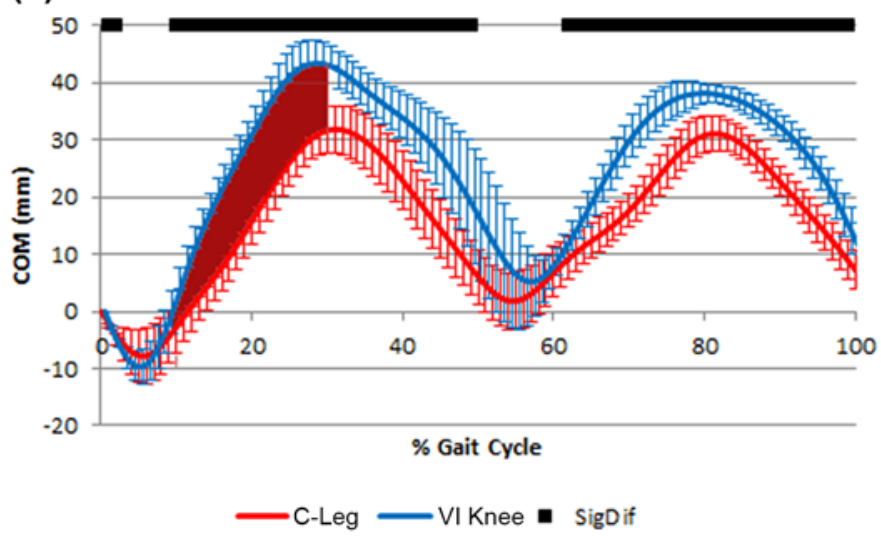

(b)

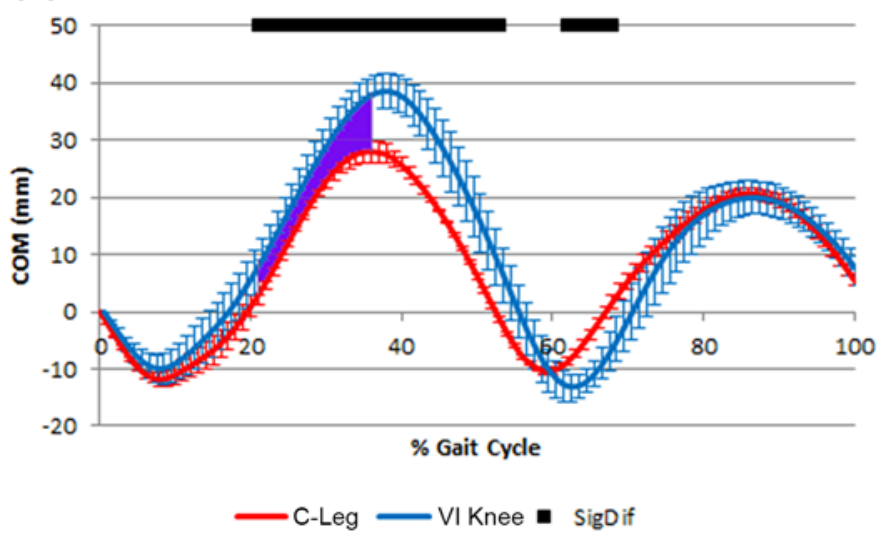

Figure 3.

Representative examples of differences in center of mass (COM) rise area while on the nonaffected leg and walking at $1 \mathrm{~m} / \mathrm{s}$. Significant differences (SigDifs) over the gait cycle between conditions are noted by the black bars over the curves. The subject in (a) raises the COM earlier and higher while using the VI Knee, resulting in a large COM rise area (red-shaded region) compared with the subject in (b), who exhibits less difference in COM rise area (purple-shaded region) between the two prostheses. The COM rise area is defined as the area of significant difference in COM height while using each prosthesis and spans from the first instance of significant difference to the point of maximum COM height during the stance phase of gait.

increasing cost. Taken together, metabolic performance at the higher speed is determined primarily by the amount of hip hiking and the resultant rise in the COM, with less effect caused by residual limb length [14].

Correlation pattern differences in the gait performance measures are a result of the amount of time to take each step. At the lower speed, subjects had enough time to walk as they felt most comfortable, with no significant differences in affected leg stance time between conditions (Table 2). This gave subjects who already use this style of gait the time needed to lift the knee to clear the toe. Longer-limbed subjects, using the affected side hip to walk, instead showed an increase in hip flexion and used the time to move the body up and forward, increasing metabolic cost [13]. At the higher speed, all subjects were more pressed for time, as seen in the decrease in stance time between conditions, with longer-limbed subjects showing the greatest reductions (Table 3). At this speed, subjects used hip hiking to help clear the toe. Those who hiked the hip and lifted the COM less showed a benefit, and those who exhibited a high degree of hip hiking and COM rise while using the VI Knee had an increased MCOT. Despite some subjects showing an increase in MCOT, all subjects self-reported that that device was more comfortable and allowed for a more relaxed gait.

These differences in performance across speeds and residual limb lengths indicate that perhaps with training, people with transfemoral amputation, including those with longer limbs, might show a reduction in metabolic cost while using the VI Knee. The issues that increased cost are not a strict function of limb length, but are correctible aspects of gait. Though all subjects were confident in using the device, experience over a period of days to weeks, instead of hours, may allow for marked improvement in gait by allowing users to become better acquainted, and work more synergistically, with the device. Perhaps by working with a prosthetist or an athome therapy program to learn to use the VI Knee more to clear the toe and hike the hip less at speeds both lower and higher than self-selected, improvements in metabolic costs could be seen across limb lengths [33]. An important topic for future research is therefore the effect of gait training on the biomechanical and energetic effect of the VI Knee on transfemoral amputees.

\section{CONCLUSIONS}

People with transfemoral amputation tend to walk more slowly, with more metabolic cost compared with nondisabled individuals. Though current microprocessorcontrolled prostheses allow users to walk more easily and newer powered knees have shown improvements over 
previous passive devices, they have yet to fully restore natural gait to people with transfemoral amputation. The novel VI Knee evaluated in this study enabled a significant improvement in the metabolic cost of gait for individuals with shorter residual limbs. While using the VI Knee, shorter-limbed subjects showed a reduction in the MCOT at the lower speed as a result of their greater tendency to lift the knee to clear the toe, reducing their COM rise. At this speed, longer-limbed subjects showed an increase in hip flexion while using the novel device and a greater amount of COM rise with a resultant increase in MCOT. At the higher speed, all subjects used hip hiking to clear the toe. Those who hiked the hip less lifted the COM less and showed an improvement in MCOT. These aspects of gait may perhaps be corrected with gait training such that all individuals with transfemoral amputation may potentially show a decrease in metabolic cost while using this device.

\section{ACKNOWLEDGMENTS}

\author{
Author Contributions: \\ Study concept and design: M. R. Williams. \\ Acquisition of data: M. R. Williams, S. D'Andrea. \\ Analysis and interpretation of data: M. R. Williams, H. Herr, S. D'Andrea. \\ Drafting of manuscript: M. R. Williams, H. Herr, S. D'Andrea. \\ Critical revision of manuscript and final approval: M. R. Williams, \\ H. Herr, S. D'Andrea. \\ Obtained funding: M. R. Williams, S. D'Andrea, H. Herr. \\ Technical and material support: H. Herr, S. D'Andrea.
}

Financial Disclosures: The authors have declared that no competing interests exist.

Funding/Support: This material was based on work supported by a VA Career Development Award (award CDA-I A7322-M), the VA Center for Restorative and Regenerative Medicine (award A3772C), and funding from the U.S. Army Medical Research and Materiel Command (award W81XWH-07-1-0689).

Additional Contributions: The authors would like to thank the staff at Rhode Island Limb for their help in assisting with VI Knee fitting, alignment, training, and tuning. M. R. Williams is now with the Cleveland FES Center and Medical Research Service, Louis Stokes Cleveland VA Medical Center, Cleveland, Ohio; and Department of Biomedical Engineering, Case Western Reserve University, Cleveland, Ohio.

Institutional Review: All participants provided informed consent. This study was approved by the Providence VA Medical Center institutional review board and conducted in accordance with federal policy for the protection of human subjects (U.S. Department of Defense).

Participant Follow-Up: The authors do not plan to inform study participants of the publication of this study unless specifically requested.

\section{REFERENCES}

1. Dillingham TR, Pezzin LE, MacKenzie EJ. Limb amputation and limb deficiency: Epidemiology and recent trends in the United States. South Med J. 2002;95(8):875-83. [PMID:12190225]

2. Mayfield JA, Reiber GE, Maynard C, Czerniecki JM, Caps MT, Sangeorzan BJ. Trends in lower limb amputation in the Veterans Health Administration, 1989-1998. J Rehabil Res Dev. 2000;37(1):23-30. [PMID:10847569]

3. Krueger CA, Wenke JC, Ficke JR. Ten years at war: Comprehensive analysis of amputation trends. J Trauma Acute Care Surg. 2012;73(6 Suppl 5):S438-44. [PMID:23192067] http://dx.doi.org/10.1097/TA.0b013e318275469c

4. Endo K, Paluska D, Herr H. A quasi-passive model of human leg function in level-ground walking. In: Proceedings of the 2006 IEEE/RSJ International Conference on Intelligent Robots and Systems; 2006 Oct 9-15; Beijing, China. New York: IEEE; 2006. p. 4935-9.

5. Pratt G, Williamson MM. Series elastic actuators. In: Proceedings of the 1995 IEEE/RSJ International Conference on Intelligent Robots and Systems: Human Robot Interaction and Cooperative Robots; 1995 Aug 5-9; Pittsburgh, Pennsylvania. Los Alamitos (CA): IEEE Computer Society Press; 1995. p. 399-406.

6. Robinson DW, Pratt JE, Paluska DJ, Pratt G. Series elastic actuator development for a biomimetic walking robot. In: Proceedings of the 1999 IEEE/ASME International Conference on Advanced Intelligent Mechatronics; 1999 Sept 19-22; Atlanta (GA). New York: IEEE; 1999. p. 561-8.

7. Winter DA, Robertson DG. Joint torque and energy patterns in normal gait. Biol Cybern. 1978;29(3):137-42. [PMID:667202] http://dx.doi.org/10.1007/BF00337349

8. DeVita P, Helseth J, Hortobagyi T. Muscles do more positive than negative work in human locomotion. J Exp Biol. 2007;210(Pt 19):3361-73. [PMID:17872990] http://dx.doi.org/10.1242/jeb.003970

9. Buckley JG, Spence WD, Solomonidis SE. Energy cost of walking: Comparison of "intelligent prosthesis" with conventional mechanism. Arch Phys Med Rehabil. 1997; 78(3):330-3. [PMID:9084360] http://dx.doi.org/10.1016/S0003-9993(97)90044-7

10. Johansson JL, Sherrill DM, Riley PO, Bonato P, Herr H. A clinical comparison of variable-damping and mechanically passive prosthetic knee devices. Am J Phys Med Rehabil. 2005;84(8):563-75. [PMID:16034225] http://dx.doi.org/10.1097/01.phm.0000174665.74933.0b

11. Waters RL, Mulroy S. The energy expenditure of normal and pathologic gait. Gait Posture. 1999;9(3):207-31. [PMID:10575082] http://dx.doi.org/10.1016/S0966-6362(99)00009-0

12. Bell JC, Wolf EJ, Schnall BL, Tis JE, Tis LL, Potter BK. Transfemoral amputations: The effect of residual limb length 
and orientation on gait analysis outcome measures. J Bone Joint Surg Am. 2013;95(5):408-14. [PMID:23467863] http://dx.doi.org/10.2106/JBJS.K.01446

13. Jaegers SM, Arendzen JH, de Jongh HJ. Prosthetic gait of unilateral transfemoral amputees: A kinematic study. Arch Phys Med Rehabil. 1995;76(8):736-43. [PMID:7632129] http://dx.doi.org/10.1016/S0003-9993(95)80528-1

14. Waters RL, Perry J, Antonelli D, Hislop H. Energy cost of walking of amputees: The influence of level of amputation. J Bone Joint Surg Am. 1976;58(1):42-6. [PMID:1249111] http://dx.doi.org/10.2106/00004623-197658010-00007

15. Bell JC, Wolf EJ, Schnall BL, Tis JE, Potter BK. Transfemoral amputations: Is there an effect of residual limb length and orientation on energy expenditure? Clin Orthop Relat Res. 2014;472(10):3055-61. [PMID:24752912] http://dx.doi.org/10.1007/s11999-014-3630-x

16. Flowers WC, Mann RW. An electrohydraulic knee-torque controller for a prosthesis simulator. J Biomech Eng. 1977; 99(1):3-8. [PMID:23720163] http://dx.doi.org/10.1115/1.3426266

17. Grimes DL, Flowers WC, Donath M. Feasibility of an active control scheme for above knee prostheses. J Biomech Eng. 1977;99(4):215-21. http://dx.doi.org/10.1115/1.3426293

18. Stein JL, Flowers WC. Stance phase control of above-knee prostheses: Knee control versus SACH foot design. J Biomech. 1987;20(1):19-28. [PMID:3558425]

http://dx.doi.org/10.1016/0021-9290(87)90263-6

19. Popovic D, Tomovic R, Tepavac D, Schwirtlich L. Control aspects of active above-knee prosthesis. Int J Man Mach Stud. 1991;35(6):751-67. http://dx.doi.org/10.1016/S0020-7373(05)80159-2

20. Popović D, Oğuztöreli MN, Stein RB. Optimal control for an above-knee prosthesis with two degrees of freedom. J Biomech. 1995;28(1):89-98. [PMID:7852445] http://dx.doi.org/10.1016/0021-9290(95)80010-7

21. Sup F, Bohara A, Goldfarb M. Design and control of a powered transfemoral prosthesis. Int J Rob Res. 2008; 27(2):263-73. [PMID:19898683] http://dx.doi.org/10.1177/0278364907084588

22. Sup F, Varol HA, Goldfarb M. Upslope walking with a powered knee and ankle prosthesis: Initial results with an amputee subject. IEEE Trans Neural Syst Rehabil Eng. 2011;19(1):71-8. [PMID:20952344] http://dx.doi.org/10.1109/TNSRE.2010.2087360

23. Wolf EJ, Everding VQ, Linberg AL, Schnall BL, Czerniecki JM, Gambel JM. Assessment of transfemoral amputees using C-Leg and Power Knee for ascending and descending inclines and steps. J Rehabil Res Dev. 2012; 49(6):831-42. [PMID:23299255] http://dx.doi.org/10.1682/JRRD.2010.12.0234

24. Wolf EJ, Everding VQ, Linberg AA, Czerniecki JM, Gambel JM. Comparison of the Power Knee and C-Leg during step-up and sit-to-stand tasks. Gait Posture. 2013;38(3): 397-402. [PMID:23375018] http://dx.doi.org/10.1016/j.gaitpost.2013.01.007
25. Martinez-Villalpando EC, Herr H. Agonist-antagonist active knee prosthesis: A preliminary study in level-ground walking. J Rehabil Res Dev. 2009;46(3):361-73. [PMID:19675988] http://dx.doi.org/10.1682/JRRD.2008.09.0131

26. Martinez-Villalpando EC, Mooney L, Elliott G, Herr H. Antagonistic active knee prosthesis. A metabolic cost of walking comparison with a variable-damping prosthetic knee. Conf Proc IEEE Eng Med Biol Soc. 2011;2011: 8519-22. [PMID:22256326] http://dx.doi.org/10.1109/IEMBS.2011.6092102

27. Williams MR, D'Andrea S, Herr HM. Impact on gait biomechanics of using an active variable impedance prosthetic knee. J Neuroeng Rehabil. 2016;13(1):54. [PMID:27283318] http://dx.doi.org/10.1186/s12984-016-0159-0

28. Robergs RA, Dwyer D, Astorino T. Recommendations for improved data processing from expired gas analysis indirect calorimetry. Sports Med. 2010;40(2):95-111. [PMID:20092364] http://dx.doi.org/10.2165/11319670-000000000-00000

29. Brockway JM. Derivation of formulae used to calculate energy expenditure in man. Hum Nutr Clin Nutr. 1987; 41(6):463-71. [PMID:3429265]

30. Cohen J, Cohen P, West SG, Aiken LS. Applied multiple regression/correlation analysis for the behavioral sciences. New York (NY): Routledge; 2013. 735 p.

31. Herr HM, Grabowski AM. Bionic ankle-foot prosthesis normalizes walking gait for persons with leg amputation. Proc Biol Sci. 2012;279(1728):457-64. [PMID:21752817] http://dx.doi.org/10.1098/rspb.2011.1194

32. Gard SA. Use of quantitative gait analysis for the evaluation of prosthetic walking performance. J Prosthet Orthot. 2006;18(1S):93-104. http://dx.doi.org/10.1097/00008526-200601001-00011

33. Darter BJ, Nielsen DH, Yack HJ, Janz KF. Home-based treadmill training to improve gait performance in persons with a chronic transfemoral amputation. Arch Phys Med Rehabil. 2013;94(12):2440-7. [PMID:23954560] http://dx.doi.org/10.1016/j.apmr.2013.08.001

Submitted for publication April 30, 2015. Accepted in revised form December 17, 2015.

This article and any supplementary material should be cited as follows:

Williams MR, Herr H, D'Andrea S. Metabolic effects of using a variable impedance prosthetic knee. J Rehabil Res Dev. 2016;53(6):1079-88. http://dx.doi.org/10.1682/JRRD.2015.04.0072

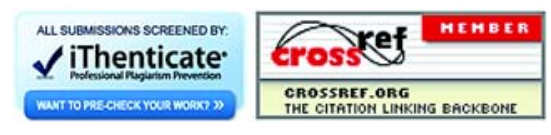


